\title{
Источники и эволюция подземных вод Хибинского массива (по данным изотопии кислорода, водорода и гелия)
}

\author{
Гудков А.В. ${ }^{1}$, Компанченко А.А. ${ }^{1}$, Мокрушина О.Д. ${ }^{1}$, Сидоров М.Ю. ${ }^{1}$, Токарев И.В. $^{2}$, \\ Толстихин И.Н. ${ }^{1}$ \\ 'Геологический институт КНЦ РАН, Anamumbl, igor.tolstikhin@gmail.com \\ ${ }^{2}$ Научный парк СПбГУ, Санкт-Петербург, пер. Декабристов, д.16
}

Аннотация. Значения $\delta^{2} \mathrm{H}$ и $\delta^{18} \mathrm{O}$ в метеорных осадках Хибин, - основных источниках питания подземных вод, - варьируют в пределах $-147 \leq \delta^{2} \mathrm{H} \leq-37 \%$, $-20 \leq \delta^{18} \mathrm{O} \leq-4 \%$ и близки к глобальной линии метеорных осадков для северного полушария (МОСП). Легкие значения с положительным дейтериевым избытком типичны для снегов и талых вод (средние значения $\delta^{2} \mathrm{H}=-106 \%, \delta^{18} \mathrm{O}=-15 \%, \Delta \delta^{2} \mathrm{H}=+5 \%$ ), а тяжелые, - с небольшим отрицательным избытком, - для дождей $\left(\delta^{2} \mathrm{H}=-65 \%, \delta^{18} \mathrm{O}=-9 \%, \Delta \delta^{2} \mathrm{H}=-2 \%\right.$ ). Поверхностные воды юго-западных склонов Хибин разгружаются в озеро Имандра, воды которого $\left(\delta^{2} \mathrm{H}=-89 \%, \delta^{18} \mathrm{O}=-12 \%\right)$ фиксируют вклады дождевых и талых вод в соотношении близком к $1 / 1$. Подземные воды района характеризуются: (1) более легкими изотопными составами, чем в озере и других открытых водоемах, - свидетельство преимущественного вклада в их баланс талых вод; (2) меньшим диапазоном вариаций отношений $\delta^{2} \mathrm{H}$ и $\delta^{18} \mathrm{O}$, отражая процесс перемешивания вод в ходе подземной миграции. Эффективность смешения, определенная по уменьшению диапазона вариации значений $\delta^{2} \mathrm{H}$ и $\delta^{18} \mathrm{O}$, близка к 0.2 . Изотопные отношения ${ }^{3} \mathrm{He} /{ }^{4} \mathrm{He}$ и ${ }^{20} \mathrm{Ne} /{ }^{4} \mathrm{He}$ позволяют выделить вклад высокощелочных алюмосодержащих сравнительно древних вод ( 5 × $10^{4}$ лет), циркулирующих в недрах Хибинского массива, в воды скважин водозабора «Центральный» и некоторых других участков. Изотопные данные позволяет ограничить вклад древних вод менее 5 \%.

Ключевые слова: подземные воды, изотопы, водород, кислород, гелий, Хибины.

\section{Sources and evolution of groundwaters of the Khibiny massif (according to the oxygen, hydrogen and helium isotope abundances)}

\author{
Gudkov A.V. ${ }^{1}$, Kompanchenko A.A. ${ }^{1}$, Mokrushina O.D. ${ }^{1}$, Sidorov M.Yu. ${ }^{1}$, Tokarev I.V. ${ }^{2}$, Tolstikhin I.N. ${ }^{1}$ \\ ${ }^{I}$ Geological Institute of the Russian Academy of Sciences, Apatity, igor.tolstikhin@gmail.com \\ ${ }_{2}^{2}$ Saint Petersburg state University Science Park, Saint Petersburg, per. 16 Dekabristov street
}

Abstract. The $\delta^{2} \mathrm{H}$ and $\delta^{18} \mathrm{O}$ values in the Khibiny precipitations, the main source of the groundwaters, vary within $-147 \leq \delta^{2} \mathrm{H} \leq-37 \%,-20 \leq \delta^{18} \mathrm{O} \leq-4 \%$ and are close to the global precipitation line for the northern hemisphere (PLNH). Light waters with a positive deuterium excess are typical for snows and melt water (average values $\delta^{2} \mathrm{H}=-106 \%, \delta^{18} \mathrm{O}=-15 \%, \Delta \delta^{2} \mathrm{H}=+5 \%$ ), and heavy waters with a slight negative excess are typical for rains $\left(\delta^{2} \mathrm{H}=-65 \%, \delta^{18} \mathrm{O}=-9 \%, \Delta \delta^{2} \mathrm{H}=-2 \%\right)$.

The surface waters of the southwestern slopes of the Khibiny are discharged into Lake Imandra; waters of the lake $\left(\delta^{2} \mathrm{H}=-89 \%, \delta^{18} \mathrm{O}=-12 \%\right)$ recorded the contributions of rain and melt waters in a ratio close to 1 . The groundwaters of the region are characterized by: (1) noticeably lighter isotopic compositions than in the lake and other open water bodies, indicating a predominant contribution of meltwater to their balance, and (2) a smaller range of $\delta^{2} \mathrm{H}$ and $\delta^{18} \mathrm{O}$ variations, reflecting the process of water mixing during underground migration.

The mixing efficiency, determined by reducing the range of $\delta^{2} \mathrm{H}$ and $\delta^{18} \mathrm{O}$ variation, is close to 0.2 . The isotopic ratios ${ }^{3} \mathrm{He} /{ }^{4} \mathrm{He}$ and ${ }^{20} \mathrm{Ne} /{ }^{4} \mathrm{He}$ allow us to distinguish a contribution of the alkaline high-Al relatively old waters $\left(\sim 5 \times 10^{4}\right.$ years $)$, migrating in the depths of the Khibiny Massif, to the waters of the wells of the "Centralny" intake and some other regions. Isotopic data allows limiting the contribution of such water to $<5 \%$.

Key words: groundwater, isotopes, hydrogen, oxygen, helium, Khibiny.

\section{введение}

Проблема формирования вод различного происхождения и состава является фундаментальной в геологии и гидрогеологии. Более того, проблема имеет важный прикладной аспект: вода необходима для жизнеобеспечения и хозяйственной деятельности человека. В связи с этим анализ современного состояния, ресурсов и качества вод, а также их изменения в результате антропогенного воздействия и быстрых климатических изменений представляется особенно актуальным. 
Наиболее перспективным для такого анализа является изотопно-геохимический подход, позволяющий охарактеризовать источники метеорных, поверхностных и подземных вод. Важнейшие сведения заключены в изотопном составе самих вод, свидетельствующем об источниках подземных вод и процессах их смешения. Данные по изотопии легких благородных газов позволяют определить время миграции подземных вод и смешение вод разного возраста и происхождения.

В этой работе основным полигоном для анализа источников и эволюции природных вод с использованием изотопных систем были выбраны южные склоны Хибинского массива, характеризующиеся достаточно плотным населением, интенсивными горно-рудными работами и, соответственно, большим потреблением питьевых и технических вод - с одной стороны, и влиянием антопогенных процессов на качество вод - с другой. До настоящего времени были выполнены немногочисленные и несистематизированные анализы изотопного состава осадков и поверхностных (преимущественно талых) вод Хибин (Чижова, 2007). Изотопный состав подземных вод практически не изучался. ${ }^{3} \mathrm{H} /{ }^{3} \mathrm{He}\left({ }^{3} \mathrm{H}\right)$ метод датирования успешно использовалась для определения возраста подземных вод водозабора «Центральный» (и некоторых других скважин и источников) и идентификации вклада древних пластово-трещинных вод массива (Kamensky et al., 1991; Гудков и др., 2014). Исследование процессов формирования метеорных, поверхностных и подземных вод осуществляется посредством систематического опробование вод, - с последующим анализом изотопного состава водорода, кислорода и благородных газов.

\section{Район и объекты опробования}

Для осуществления работ по исследованию источников и баланса вод юго-западных склонов Хибин отбирались и анализировались образцы осадков (дождя и снега), вод открытых водоемов (рек и озер) и подземных вод, - водозаборных скважин и самоизливающихся источников. Кроме того, для исследования эволюции изотопного состава пробы воды отбирались несколько раз в году в одних и тех же пунктах опробования.

Для анализа подземных вод опробовались скважины водозаборов «Центральный», «Ключевой», «Коашва», самоизливающиеся скважины в поселке Юкспоррйок, на «23 км» дороги Апатиты - Кукисвумчорр, и другие. Кроме того, опробовались источники подземных вод, используемые населением для питьевого водоснабжения. Методика отбора и анализа проб подземных вод опубликована в работах Гудкова и др. (2014, 2020).

\section{Метеорные осадки и поверхностные воды}

Изотопные составы водорода и кислорода метеорных осадков юго-западных склонов Хибин варьируют в дождевых водах и снегах в пределах $-95 \leq \delta^{2} \mathrm{H}_{\text {дождь }} \leq-37 \%$, $-13 \leq \delta^{18} \mathrm{O}_{\text {дождь }} \leq-4 \%$, $-147 \leq \delta^{2} \mathrm{H}_{\text {Снег }} \leq-95 \%,-20 \leq \delta^{18} \mathrm{O}_{\text {Снег }} \leq-13 \%$. Распределение значений $\delta^{2} \mathrm{H}$ и $\delta^{18} \mathrm{O}$ близко к глобальной линии метеорных осадков северного полушария (МОСП на рис. 1), определяемой уравнением $\delta^{2} \mathrm{H}=8.1 \delta^{18} \mathrm{O}+11 \%$ (Dansgaard, 1964). Сопоставление среднегодовой температуры $\left(\mathrm{T},{ }^{\circ} \mathrm{C}\right)$ peгиона с изотопным составом снега в нем показало, что эти два параметра коррелируют (см. рис. 3 в Dansgaard, 1964) с линией регрессии $\delta^{18} \mathrm{O}=0.69 \mathrm{~T}-13.6 \%$. Для среднего изотопного состава кислорода в снегах и талых водах Хибин, $\delta^{18} \mathrm{O}=-15 \%$ (рис. 1), это уравнение регрессии дает среднегодовую температуру $-2^{\circ} \mathrm{C}$ - близкую к наблюдаемой на склонах Хибин. Согласно этим результатам, равновесные процессы фракционирования в ходе формирования осадков Хибин играли главную роль. Отклонение точек от линии МОСП, - «дейтериевый избыток», - свидетельствует о вкладе и неравновесных процессов.

Данные по изотопии вод открытых водоемов во всех случаях находятся в пределах или вблизи полей, определенных осадками района, снегами и дождями. Изотопия вод открытых водоемов варьирует в пределах от $-115 \leq \delta^{2} \mathrm{H} \leq-87 \%$ o, $-15 \leq \delta^{18} \mathrm{O} \leq-11.5 \%$, т.е. в более узком диапазоне по сравнению с осадками: наглядно виден главный эффект течения поверхностных вод, - перемешивание вод разных источников. Эволюция изотопии вод в течение года, - особенно в близких к склонам Хибин водоемах, - в основном диктуется временем таяния снегов на вершинах и склонах гор. 


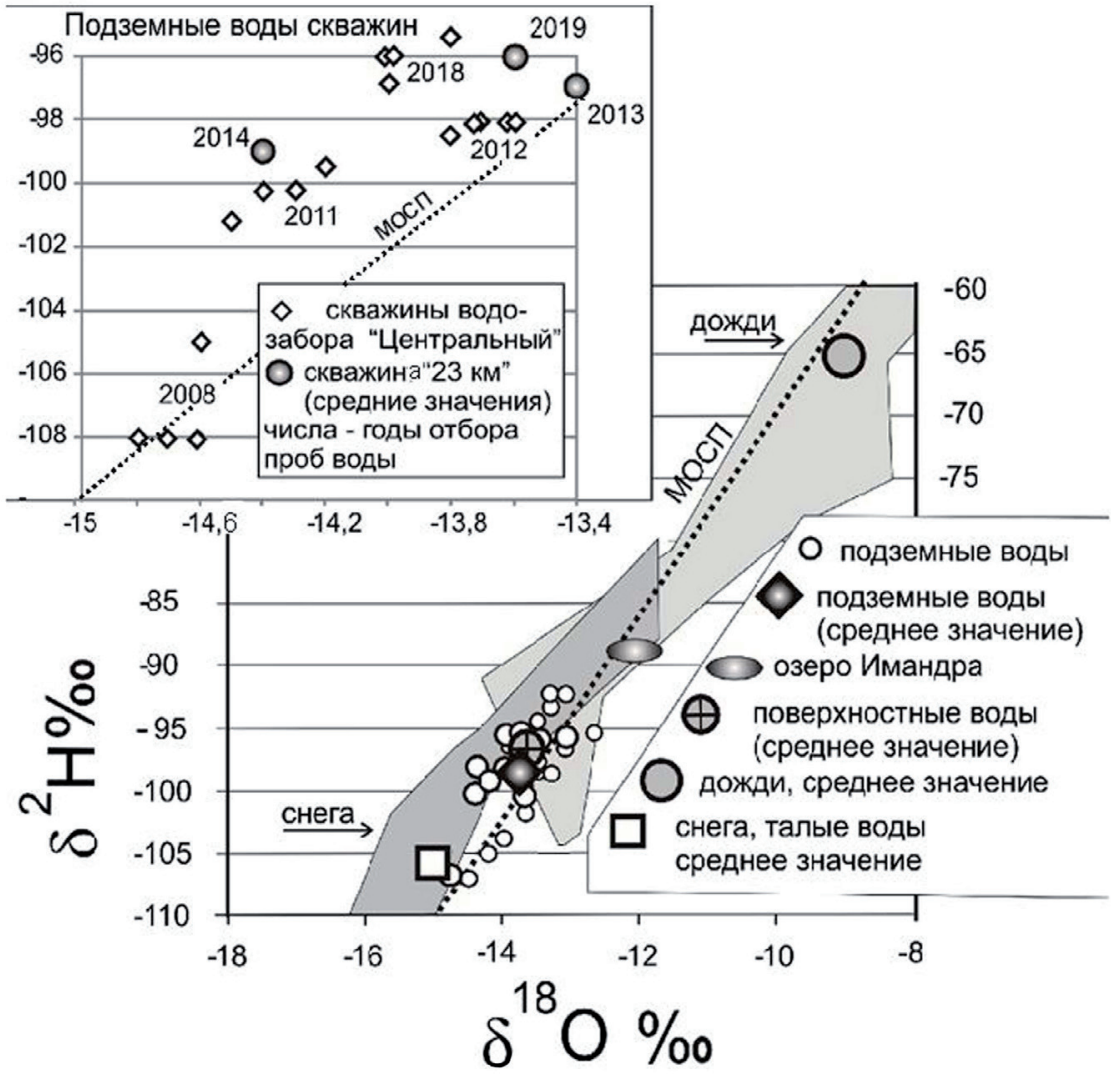

Рис. 1. Изотопный состав подземных вод в сравнении с метеорными осадками юго-западных склонов Хибин (Кировский и Апатитский районы). Дожди - область со светло-серой заливкой; снега - темно-серая заливка); маленькие кружки - единичные измерения; большие кружки - средние значения для данного объекта за год. На врезке: изотопный состава вод скважин водозабора «Центральный» и «23 км».

Fig. 1. Isotope composition of ground waters in comparison with meteor showers of the south-west Khibiny slopes (Kirovsk and Apatity districts). Rains - area filled with light grey; snow - area filled with dark grey); small circles single measurements; big circles - mean values for this object over a year. The inset shows an isotope composition of waters from boreholes of the "Central" and "23 km" water-intake facilities.

Воды, отобранные в период интенсивного таяния (обычно конец мая - июнь), характеризуются легкими, близкими к типичным для снега и талых вод значениями $\delta^{2} \mathrm{H}$ и $\delta^{18} \mathrm{O}$, а воды позднего лета ранней осени, преимущественными источниками которых являются дожди, характеризуются более тяжелой водой. Соотношение талых вод и метеорных (дождевых) вод в водном балансе основного базиса дренирования - озера Имандры - близко к 1:1.

\section{Подземные воды}

Изотопия подземных вод укладывается в еще более узкий диапазон по сравнению с водами открытых водоемов $-107 \leq \delta^{2} \mathrm{H} \leq-92 \%$, $-15 \leq \delta^{18} \mathrm{O} \leq-12.5 \%$ (рис. 1 ). Средние значения $\delta^{2} \mathrm{H}$ и $\delta^{18} \mathrm{O}$ подземных вод близки к таковым в водах открытых водоемов. Согласно изотопным данным, основными источниками подземных вод являются дождевые и талые воды, миграция которых сквозь пористо - трещинную среду приводит к перемешиванию вод этих источников. Для полуколичественных оценок и сравнений можно рассматривать «параметр смешения», - отношение (R) наблюдаемых различий изотопных составов подземных вод одного и того же источника в разное время $t_{1}$ и $t_{2}$, $\Delta\left(\delta^{18} \mathrm{O}\right)_{\text {пв }}=\delta^{18} \mathrm{O}\left(t_{1}\right)-\delta^{18} \mathrm{O}\left(t_{2}\right)$, и гипотетических «входных» различий между талыми $\delta^{18} \mathrm{O}_{\mathrm{TB}}$ и метеорными $\delta^{18} \mathrm{O}_{\mathrm{MB}}$ водами региона:

$$
\mathrm{R}=\Delta\left(\delta^{18} \mathrm{O}\right)_{\Pi \mathrm{BB}} /\left(\delta^{18} \mathrm{O}_{\mathrm{MB}}-\delta^{18} \mathrm{O}_{\mathrm{TB}}\right)
$$


Согласно врезке на рис. 1, наблюдаемое различие изотопии кислорода для подземных вод водозабора «Центральный» $\Delta\left(\delta^{18} \mathrm{O}\right)_{\Pi в}=\delta^{18} \mathrm{O}(2008)-\delta^{18} \mathrm{O}(2012) \cong-1 \%$. Предположим, что источниками вод водозабора были «средний талый снег» $\delta^{18} \mathrm{O}_{\mathrm{TB}}=-15 \%$ и «средний» дождь $\delta^{18} \mathrm{O}_{\mathrm{MB}}=-9 \%$ (рис. 1). Тогда параметр смешения по кислороду близок к 0.17 . Повторив этот расчет для дейтерия, получим $\mathrm{R} \cong 0.2$. Заметное различие изотопии воды в разные годы наблюдается и для скважины 23 .

Следует отметить, что возрасты вод - время подземной фильтрации и перемешивания - для этих скважин существенно различны. Возраст вод водозабора «Центральный» надежно определен ${ }^{3} \mathrm{H}-{ }^{3} \mathrm{He}\left({ }^{3} \mathrm{H}\right)$ методом и составляет $21 \pm 1.5$ года, в то время как возраст воды скважины «23 км» находится в пределах погрешности датирования (менее года). Наиболее тяжелая вода обнаружена в воде скважины, отобранной в январе (2019 г.). Тяжелая вода типична для осадков, выпадающих в конце лета. Таким образом, возраст воды скважины «23» км, вероятно, близок к 0.5 года. Эти наблюдения можно интерпретировать как свидетельство преимущественно поршневого характера фильтрации подземных вод, позволяющему сохранять изотопную неоднородность воды независимо от ее возраста.

${ }^{3} \mathrm{H}-{ }^{3} \mathrm{He}\left({ }^{3} \mathrm{H}\right)$ данные свидетельствуют о небольшом вкладе «древних» вод в подземные воды рассматриваемого района. Исследование вод водозабора «Центральный» позволило оценить величину этого вклада, $\sim 5 \%$, примерный возраст древних вод, $\sim 50,000$ лет, и изотопное отношение ${ }^{3} \mathrm{He} /{ }^{4} \mathrm{He}$ в этих водах, $\sim 2 \times 10^{-7}$ (Kamensky et al., 1991; Гудков и др., 2014). Исследование вод водозабора в разные годы показало, что величина этого вклада в воды конкретной скважины не постоянна.

Примерная оценка вклада древних вод может быть выполнена и на основании изотопии кислорода. В породах мантийных плюмов, характеризующихся высокими отношениями ${ }^{3} \mathrm{He} /{ }^{4} \mathrm{He}$ (а именно к таким плюмам относятся девонские интрузии Кольского полуострова, Tolstikhin et al., 2002), значение $\delta^{18} \mathrm{O}$ примерно постоянно и близко к +5 \% (Starkey et al., 2016). Несколько образцов воды в нижней части рисунка 1 находятся вправо от линии МОСП, хотя для таких вод типичен положительный водородный избыток. Действительно, большинство образцов и среднее значение для талых вод расположено вправо от этой линии (рис. 1; см. также Dansgaard, 1964). Предположим, что увеличение $\delta^{18} \mathrm{O}$ в некоторых образцах на $~ 1 \%$ (с -15 \%о до - $14 \%$ ) произошло из-за добавки древней воды, изотопно-равновесной с породами плюма $\left(\delta^{18} \mathrm{O}_{\text {дв }}=5 \%\right)$. Обозначая фракцию древней воды в уравнении баланса $\Phi$

$$
\delta^{18} \mathrm{O}_{\text {дв }} \times \Phi+\delta^{18} \mathrm{O}_{\text {мв }}(1-\Phi)=\delta^{18} \mathrm{O}_{\text {ОБ }}
$$

и подставляя значения $\delta^{18} \mathrm{O}$ в «молодой воде» $\delta^{18} \mathrm{O}_{\mathrm{MB}}=-15 \%$ и измеренные значения в образцах $\delta^{18} \mathrm{O}_{\mathrm{MB}}=-14 \%$ (рис. 1 ), получаем, в рамках такого предположения, вклад древней воды $\sim 5 \%$, в соответствии с независимой оценкой, выполненной на основании изотопного анализа благородных газов.

Изучение пород Хибинского массива свидетельствует о том, что Не с отношением ${ }^{3} \mathrm{He} /{ }^{4} \mathrm{He} \sim 2 \times 10^{-7}$ мог выделиться из пород в подземные воды как при дроблении пород, так и при их нагреве. При дроблении из пород массива выделен Не с отношением ${ }^{3} \mathrm{He} /{ }^{4} \mathrm{He}$ изменяющимся в пределах от $3 \times 10^{-8}$ до $1 \times 10^{-6}$ при среднем значении (для 10 образцов) $4 \times 10^{-7}$. Среднее отношение ${ }^{3} \mathrm{He} /{ }^{4} \mathrm{He}$ в породах южных Хибин (хибинит, уртит, апатит-нефелиновые руды) близко к $2 \times 10^{-7}$.

\section{Заключение}

Измеренные значения $\delta^{2} \mathrm{H}$ и $\delta^{18} \mathrm{O}$ в осадках Хибин варьируют в широких пределах $-147 \leq \delta^{2} \mathrm{H} \leq-37 \%,-20 \leq \delta^{18} \mathrm{O} \leq-4 \%$, - в соответствии с метеорными осадками северного полушария. Легкие значения с положительным дейтериевым избытком типичны для снега и талых вод, а тяжелые, - с небольшим отрицательным избытком, - для дождей. В подземных водах эти отношения изменяются в существенно более узком диапазоне, $-107 \leq \delta^{2} \mathrm{H} \leq-92 \%$, $-15 \leq \delta^{18} \mathrm{O} \leq-12.5 \%$, свидетельствуя о том, что талые воды и дожди являются главными источниками подземных вод и что в ходе подземной миграции происходит смешение вод этих источников. Измерения изотопного состава и концентраций $\mathrm{He}, \mathrm{Ne}$ и ${ }^{3} \mathrm{H}-{ }^{3} \mathrm{He}\left({ }^{3} \mathrm{H}\right)$ датирование позволяют выделить вклад «древних» вод в воды водозабора «Центральный» и некоторых других скважин и источников. Межгодовые вариации изотопного состава вод свидетельствует об их неполном перемешивании в ходе $~ 20$-летней миграции, указывая на близкий к поршневому характер фильтрационного процесса. 
Работа продержана грантом РФФИ 18-05-70004, «Ресурсы Арктики».

\section{Литература}

1. Гудков А.В. и др. Тритий-гелий-3 метод и его применение для датирования подземных вод (на примере Кировского горнопромышленного района, Мурманская область // Геохимия. 2014. Вып. 7. С. 646-654.

2. Гудков А.В. и др. Формирование и баланс метеорных осадков, поверхностных и подземных вод южных склонов Хибинского массива (по данным изотопии кислорода и водорода) // Направлена в журнал «Водные Ресурсы». 2020.

3. Чижова Ю.Н. Изотопно-геохимические особенности снежного покрова и ледникового льда в разных гляциологических условиях Приэльбрусья, Полярного Урала и Хибин // Дис. уч. ст. канд. географ. наук // Москва. РГБ. 2006. 178 с.

4. Dansgaard W. Stable isotopes in precipitation // Tellus. 1964. V. 16. P. 436-468.

5. Kamensky I.L. et al. ${ }^{3} \mathrm{H}-{ }^{3} \mathrm{He}$ dating: A case for mixing of young and old groundwaters // Geochemica et Cosmochemica Acta. 1991. V. 55. P. 2895-2899.

6. Starkey N.A. et al. Triple oxygen isotopic composition of the high- ${ }^{3} \mathrm{He} /{ }^{4} \mathrm{He}$ mantle // Geochim. Cosmochim. Acta. 2016. V. 176. P. 227-238.

7. Tolstikhin I.N. et al. Rare gas isotopes and parent trace elements in ultrabasic-alkaline-carbonatite complexes Kola Peninsula: Identification of lower mantle plume component // Geochim. Cosmochim. Acta. 2002. V. 66 (5). P. 881-901. 